\title{
Design of a synthetic jet actuator for flow separation control
}

\author{
Perez Weigel $^{1} \cdot$ Martin Schüller ${ }^{1} \cdot$ André Gratias $^{1} \cdot$ Mathias Lipowski $^{1} \cdot$ Theo ter Meer $^{2} \cdot$ Michiel Bardet $^{2}$
}

Received: 22 March 2018 / Revised: 9 October 2020 / Accepted: 12 October 2020 / Published online: 21 October 2020

(c) The Author(s) 2020

\begin{abstract}
This paper describes the development of a piezo-electric synthetic jet actuator (SJA) of the AFLoNext project. Active flow-loads and noise control on next generation wing (AFLoNext) is a project within European Union's 7th Framework Program. One of the main project goals is the application of active flow control (AFC) techniques, such as SJAs and pulsed jet actuators (PJAs) in two different application scenarios to evaluate the potential benefit for retrofit of current aircraft and also for future aircraft designs. This paper is focusing on the SJAs. For large-scale wind tunnel testing, an actuator panel with 84 SJAs including the drive electronics system was designed and pre-tested in a laboratory environment. The performance exceeds $100 \mathrm{~m} / \mathrm{s}$ with outlet nozzles of $2.5 \mathrm{~mm}$ diameter and a span wise clearance of $10 \mathrm{~mm}$. A second actuator design was prepared for the application on the outer wing region and was investigated in a harsh environmental test campaign. Two span wise rows of five actuators were integrated in a panel with $10 \times 0.5 \mathrm{~mm}^{2}$ slotted outlet nozzles. With this design also velocities exceeding $100 \mathrm{~m} / \mathrm{s}$ were measured. The actuators withstand different harsh environmental conditions including extreme temperature, rain, mechanical vibration and shock. With the results of the project, a technology readiness level (TRL) evaluation will conclude the maturity of the technology. Depending on the final test and evaluation results, achievement of TRL4 is expected.
\end{abstract}

Keywords Synthetic jet actuator · Flow separation control · Robustness test campaign · Wind tunnel evaluation

\section{Introduction}

\subsection{AFLoNext technology streams}

AFLoNext is a project within the European Union's 7th Framework Program. One of the main goals is the application of active flow control (AFC) techniques, such as synthetic jet actuators (SJAs) and pulsed jet actuators (PJAs) in two different application scenarios to evaluate the potential benefit for retrofit of current aircraft and also for future aircraft designs. An overview of the different technology streams (TS) in the project is depicted in Fig. 1. In TS2, the application of synthetic jet actuators on the outer wing region is evaluated. For the actuator development in TS2 the focus was on the robustness of the system. A detailed test

Perez Weigel

perez.weigel@enas.fraunhofer.de

1 Fraunhofer Institute for Electronic Nano Systems ENAS, Technologie-Campus 3, 09126 Chemnitz, Germany

2 NLR - Netherlands Aerospace Centre, Anthony Fokkerweg 2, 1059 CM Amsterdam, The Netherlands campaign for the assessment of the system in different harsh environmental conditions was performed. A second application scenario is evaluated in TS3. The actuators are applied on the wing/pylon junction to counter the lift losses caused by the closely coupled integration of ultra-high bypass ratio (UHBR) turbofan engines. The other Technology Streams within the project deal with other approaches for reducing emissions for future aircraft, such as hybrid laminar flow control or noise and vibration mitigation.

\subsection{Review state of the art}

It has been known for two decades that SJAs are able to manipulate an air flow [1, 2]. This effect can be used for fluidic active flow control, especially for aerospace applications $[3,4]$. Apart from this, their potential application field is very wide. SJAs can be used for cooling in electronic devices [5], jet vectoring [6], pumping, mixing enhancement and for many other purposes $[7,8]$. The device basically consists of a small cavity which acts as a fluidic resonator and which is closed on one side by a vibrating transducer element. A nozzle through the cavity wall connects the cavity 
Fig. 1 Overview of technology streams for the AFLoNext project. (Source: https://www. aflonext.eu/technology-hybri d-laminar-flow-active-flowcontrol-noise-reduction-vibra tions-mitigation-8)

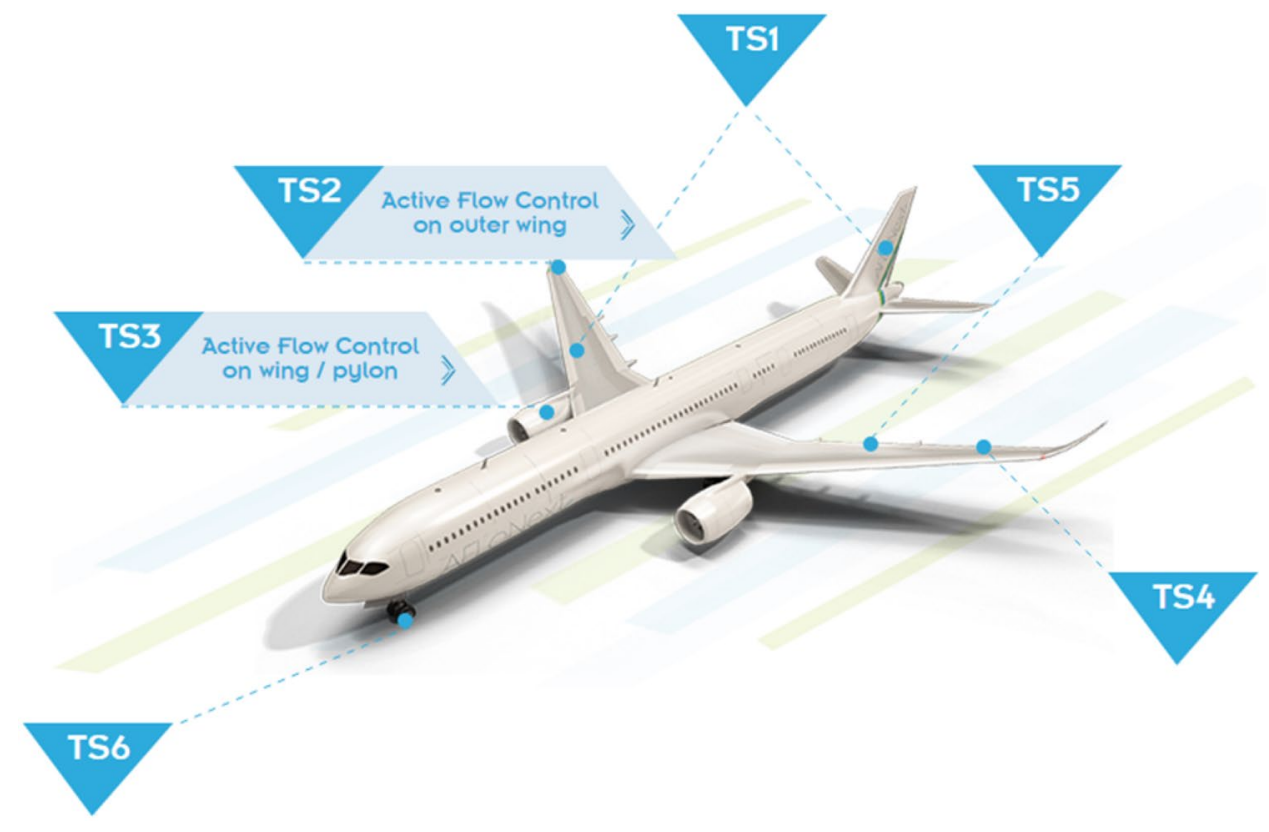

with the external environment. The vibration of the transducer element leads to a periodic suction and exhausting of the surrounding fluid through the nozzle. Due to the pulsed blowing, a synthetic jet is formed in front of the nozzle, even if the net mass flow through the actuator is zero [1]. The motion of air out of the nozzle differs in direction and characteristics from that of the undirected ingestion of air into the cavity. This forms a train of vortices, or vortex rings, which induce a velocity field that constitutes the synthetic jet. The advantages of SJAs are that they do not need an external compressed air supply (e.g., like PJAs), are relatively small and have a low power consumption. Challenging is their limited performance with respect to possible peak velocities and the interdependence of the resonance behaviour and environmental conditions [9]. The development in AFLoNext aims at a progress towards feasible actuators for integration in flow control systems for future aircraft. The identified drawbacks of the actuators are addressed and the designs focus on both aspects-high performance as well as high robustness - to meet industrial requirements for which high exit velocities $(>100 \mathrm{~m} / \mathrm{s})$ and long life times of several years are necessary.

The majority of the described actuators in literature uses piezo-electric transducers [10-15], but also actuators with shape-memory alloy-based transducers [16] or mechanical actuators with a piston $[17,18]$ are used to drive SJAs. Next to this kind of transducers also actuators with electrodynamic transducers are described [19]. The different geometrical parameters of the actuators make an overall benchmark of different prototypes difficult, because the peak velocity depends on drive frequency, nozzle geometry, cavity volume and even the clamping method used for the transducer element. A review of the current state of the art has identified four main aspects for further optimization of the SJAs:

- Calculations and simulations for optimization of transducer force and deflection;

- Modelling and optimization of geometrical parameters of the fluidic resonator;

- Optimization of clamping and connection of electrical contacts required for integration of transducer elements;

- Increased robustness against harsh environmental conditions.

The requirements given by the industrial partners cover constraints of the following aspects:

- System installation and space available for assembly.

- Active flow control performance.

- Energy consumption.

- Materials.

- Operability.

- Redundancy.

- Structural considerations.

- Weight.

Not all requirements apply to the hardware system which is evaluated in wind tunnel tests. The focus has been the bold marked aspects above to keep the effort in line with the intended technology readiness level (TRL) of 3-4 and the available time. All other aspects will be addressed in further developments of the actuator system towards a future flight test. 


\section{Active flow control for the wing/pylon junction}

\subsection{Concept for wind tunnel evaluation}

The main goal of the system design was the compliance with the requirements that apply to the integration in a 1:1-scale wind tunnel model. Because of the limited budget and time, and the targeted TRL, a flexible solution with a limited number of channels has been developed with the option to further miniaturize and integrate the system in future design iterations. The final specification of the actuators was not available during the design phase of the system, so certain assumptions had to be made. This led to a modular approach of the system. Changes to the system can be made more easily than to fully integrated systems.

An overview of the complete system design for the SJA AFC system is shown in Fig. 2. It consists of three main parts:

- The SJA insert box for the housing of the actuators and the integration in the wing section of the wind tunnel model;

- Signal conditioning, actuator excitation and monitoring equipment, located as close as possible to the wind tunnel model (drive electronics subracks);

- The human-machine interface (HMI) computer for control, data recording and visualisation.

The drive electronics system consists of two high voltage (HV) amplifier subracks that are controlled by a measurement control (M\&C) subrack. It provides highvoltage excitation signals from 0 up to $200 \mathrm{~V}$ for the actuators. It also monitors the current status of the system and the status of the individual actuators.

\subsection{Design wind tunnel test actuator}

The synthetic jet actuators developed in AFLoNext are based on piezo-electric transducers. They are equipped with a twopin electrical connector for the HV input signal and an outlet on the upper side of the housing. The outlet is inclined by $45^{\circ}$ in flow direction and has a circular cross section with a diameter of $2.5 \mathrm{~mm}$ and a mean length of $3.0 \mathrm{~mm}$. The outlet has a sealing for an air tight connection with a common top cover plate. The actuators have a polymeric housing (Fig. 3).

The transducer used for this setup is a bimorph structure with a diameter of $35 \mathrm{~mm}$ which consists of a soft PZT with high $\mathrm{d} 31$ and a spring steel as substrate with a thickness of $200 \mu \mathrm{m}$ each. The electrical parameters of the piezo-electric transducer determine the design of the drive electronics system. The following parameters were used to calculate the required amplifier power:

- Capacitance of transducer element: up to $200 \mathrm{nF}$;

- Drive frequency in the first mechanical resonance of the transducer: up to $2.0 \mathrm{kHz}$;

- Maximum excitation voltage: $200 \mathrm{~V}_{\mathrm{pp}}$ (unipolar).

Figure 4 shows the typical frequency-dependent performance of three SJAs with two main resonance frequencies in the velocity plot: the Helmholtz frequency (at approx. $750 \mathrm{~Hz})$ and the mechanical resonance frequency of the transducer element (at approx. $1500 \mathrm{~Hz}$ ). The velocities have been acquired using a hot-wire system in a dedicated test setup for the integrated actuators. The measurement has been performed without cross flow at a distance of $1 \mathrm{~mm}$ above the centre of the orifice. For this design, velocities up to $100 \mathrm{~m} / \mathrm{s}$ are possible with a peak to peak current consumption of 0.15-0.2 A per actuator at the mechanical resonance frequency. At this frequency, the power consumption of an actuator can be calculated using the average current $I_{\mathrm{av}}=\frac{1}{\pi} \cdot I_{\mathrm{pk}}$. With $200 \mathrm{~V}$ excitation voltage the power consumption of one actuator is $9.6-12.7 \mathrm{~W}$.
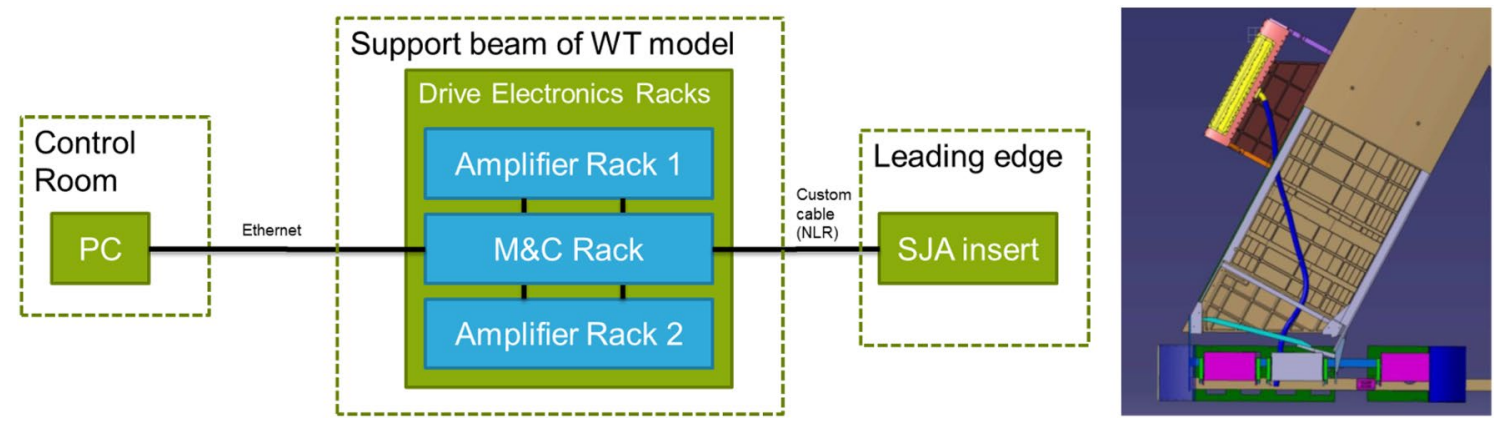

Fig. 2 Concept system design for the SJA system (left), top view of wind tunnel model CAD model with SJA insert box (yellow), custom actuator connection cable (blue), and drive electronics subracks (magenta and grey) 
Fig. 3 Synthetic jet actuator

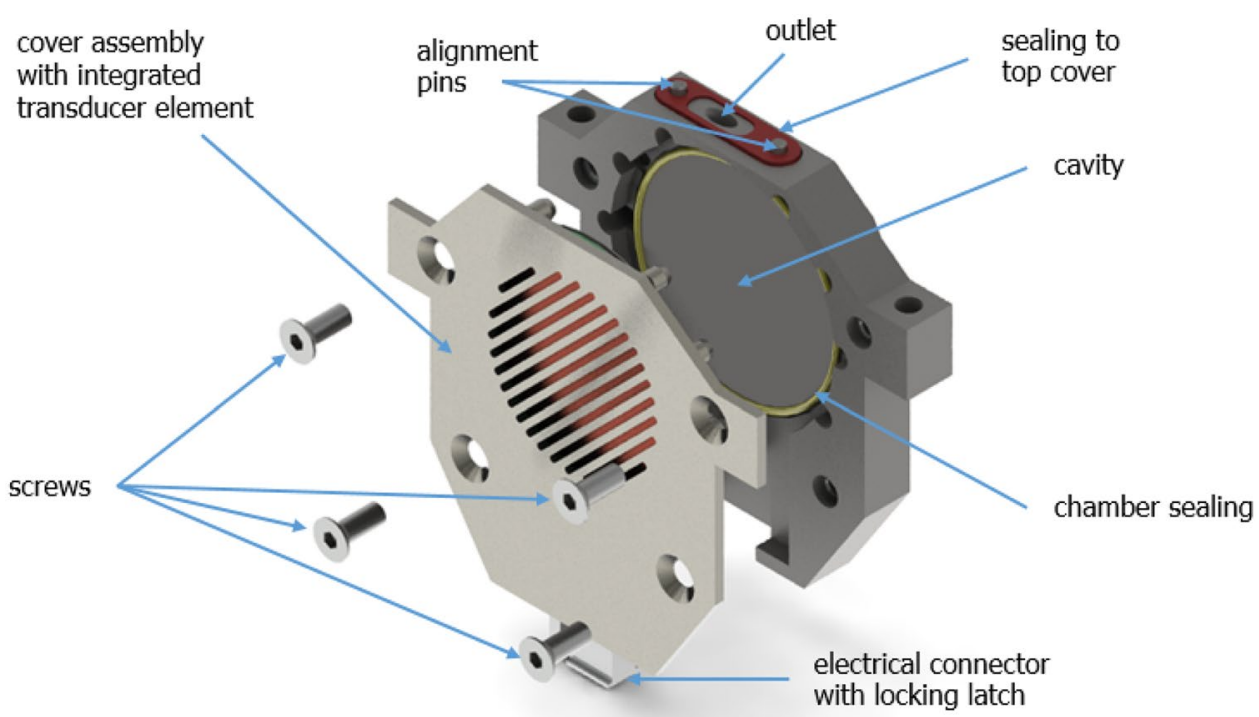

Fig. 4 Actuator velocity and current versus frequency

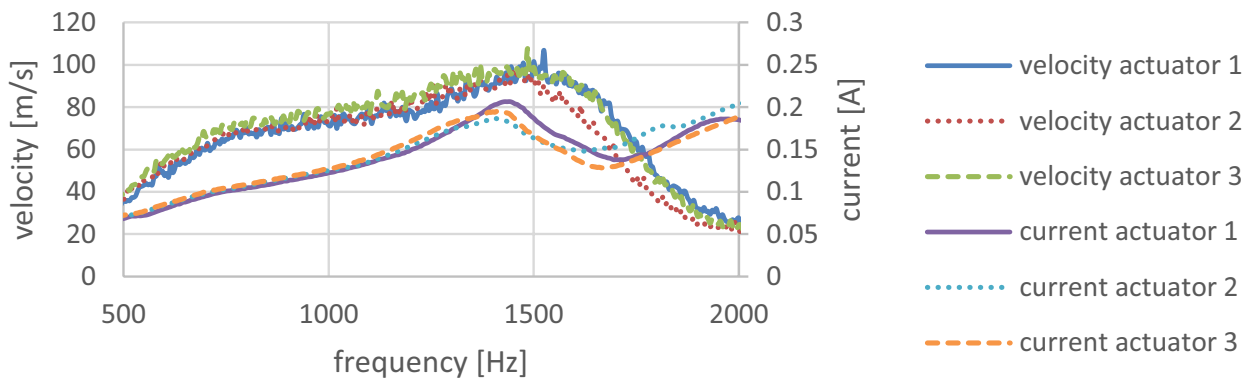

The three actuators, which performance is shown in Fig. 4 have the same geometries and dimensions. The differences between the results in the plots are mainly caused by manufacturing tolerances of the transducer elements. The exit velocities and the resonance frequencies are not influenced dramatically by those tolerances, but this behaviour needs to be taken into account for the control of the actuators and the design of the driving electronics.

\subsection{Drive electronics design}

\subsubsection{Amplifier subrack}

The initial aim of the drive electronics for the SJAs was to focus on the use of Commercial Off-The-Shelf (COTS) equipment as a complete solution to drive all required actuators. The leading specifications were the ability to drive large capacitive loads (100 SJAs of $200 \mathrm{nF}$ each) in combination with sinewave excitation voltages of at least $150 \mathrm{~V}_{\mathrm{pp}}$ and a frequency of $3 \mathrm{kHz}$. Because of the required high full power bandwidth, with the associated high slew rate, this leads to HV amplifiers that must be able to deliver a current of about $28 \mathrm{~A}_{\mathrm{p}}$ in total for all actuators. COTS products with such specifications (total power exceeding $2 \mathrm{kVA}$ ) were not found on the market. For this application, only high voltage power amplifiers that are specifically designed for driving reactive loads are usable, as conventional amplifiers suffer from stability problems and have difficulty coping with the high power dissipation in the power stage which are suitable for this application. Moreover flexible grouping of actuators is desired with the option to drive various groups with different signals. The high total power demand and the grouping requirement called for a more flexible custom-made solution based on smaller COTS HV driver amplifiers. Various desktop and modular amplifiers were evaluated, amongst others from manufacturers such as Trek, Physik Instrumente, Sonitron, Tegam, Piezo Systems, and PiezoDrive. The most appropriate amplifiers with regard to technical performance, compactness, and price are manufactured by PiezoDrive. The selected amplifier module is a fan-cooled OEM module from PiezoDrive, type MX200 [20]. This module can be configured for a maximum amplitude of 100, 150, or $200 \mathrm{~V}_{\mathrm{pp}}$. Maximum output current depends on the selected voltage mode. The maximum output current for the $200 \mathrm{~V}_{\mathrm{pp}}$ 


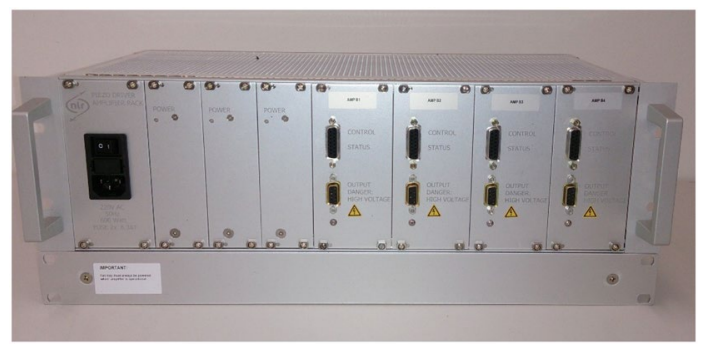

Fig. 5 Amplifier subrack-front view

setting is $220 \mathrm{~mA}_{\mathrm{RMS}}$ and $1 \mathrm{~A}_{\mathrm{p}}$. This corresponds to driving $250 \mathrm{nF}$ at $2 \mathrm{kHz}$ at $200 \mathrm{~V}_{\mathrm{pp}}$. The output is current limited and tolerates overloading and short circuiting, making it a robust solution.

An amplifier subrack (Fig. 5) is designed and manufactured which contains twelve MX200 amplifier modules and the DC power supplies for the amplifiers. Three amplifier modules are combined on one carrier board; four carrier boards and two COTS power supply modules [21] are incorporated in one amplifier rack. The subrack is a $19^{\prime \prime}$ unit with perforated top and bottom panels. They allow ventilation while at the same time shielding the dangerous voltages of the amplifier modules. A fan tray is fixed to the bottom of the rack, to remove the heat that is generated in the amplifier modules.

\subsubsection{Measurement and control subrack}

Monitoring of the actuators is necessary to have a feedback on the actual behaviour during the tests. Different approaches for the monitoring can be used, but these have to be feasible in terms of integration, costs and handling. A characterization of the performance with conventional air speed measurements like hot-wire anemometry or pitot tubes are not possible during the tests. Hot-wire sensors would need to withstand the harsh environmental conditions and might get damaged by particles. Pitot tube systems have the drawback of low-pass filtering the velocity signal due to fluidic capacitance in the tube and therefore can only be used at low frequencies. Furthermore the integration of such a sensor into the nozzle structures would be very challenging in terms of integration aspects. A second solution is to monitor the pressure in the cavity of the actuators and the outer pressure to calculate the velocity through the nozzle based on the pressure difference with common analytical equations. Small pressure sensors which can measure the cavity pressure fast and accurately, however, are too expensive for integration in each actuator. Therefore, it is only possible to measure the electrical characteristics of actuator voltage and current consumption to provide feedback of the actuator behaviour. The dynamic behaviour of the actuator can be observed by measuring the frequency-dependent current consumption and the phase angle between voltage and current signal.

Figure 6 shows the connection between the Amplifier subracks, the measurement and control (M\&C) subrack and the actuators. The HV signal of the amplifiers is routed through the M\&C subrack. In this subrack, a measurement circuit monitors the voltage and current signal. From the M\&C subrack, the HV signal is connected to the actuators. Up to four actuators can be connected in parallel to a single output of the M\&C subrack, which requires 7 outputs to drive 84 single actuators in total.

The M\&C subrack has integrated microcontroller-based data acquisition circuits. The microcontrollers measure the signals' current and voltage. Moreover, they provide an analogue input signal for the HV amplifiers. The subrack is only functional when it is connected to a remote measurement computer. A software application on this computer provides a user interface to control the subrack and setup the drive signals as well as collect the data measured by the microcontrollers.

\subsubsection{Cabling}

Cable harnesses were manufactured for the signal exchange between the M\&C subrack and the two Amplifier subracks, and also for connecting the actuators to the $\mathrm{M} \& \mathrm{C}$ subrack. The latter cables are 5 meters long. They carry potentially lethal signals and are manufactured using high-voltage wire in twisted pairs. Sets of these twisted pairs are contained in braids that provide a protective shield that ensures safety even in case a cable is damaged mechanically. Inductance of the long cable needs to be kept below a specified value,

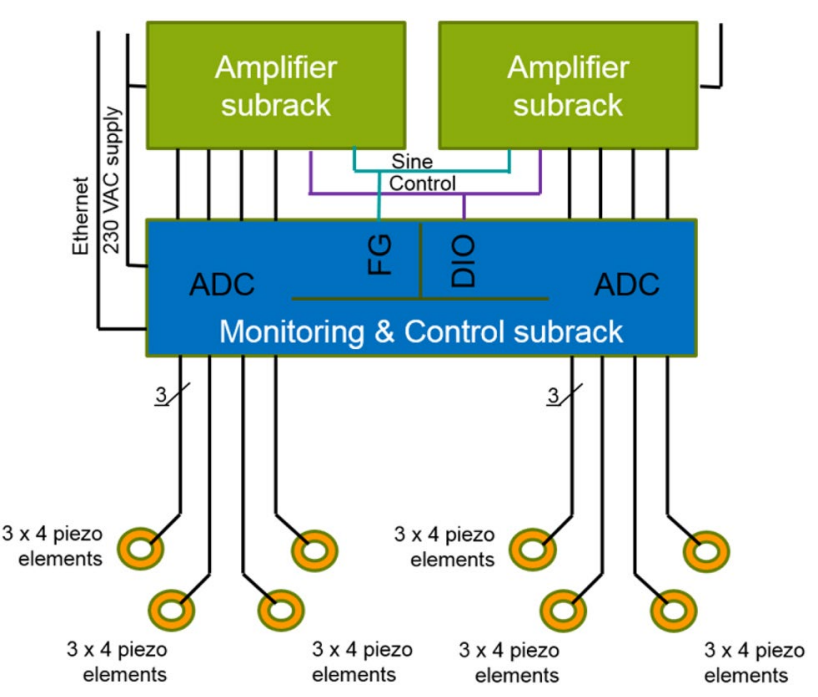

Fig. 6 System design for AFLoNext SJA system ( $A D C$ analog-digital converter, $F G$ function generator, $D I O$ digital input/output) 
to avoid resonance with the SJA capacitance at a frequency in or close to the signal bandwidth.

\subsubsection{Software}

The windows software for control of the M\&C subrack is implemented in $\mathrm{C \#}$ programming language. It can be used to set up the drive parameters for every amplifier and measure the voltage and current of every channel out of the total of 24 channels. Furthermore, it monitors the overload status of the amplifiers and gives the possibility to enable or disable individual amplifiers. For identifying the resonance behaviour of the actuators and track if there are changes related to the different outer flow conditions, the software is capable of performing a frequency sweep and providing data for plots of peak current versus frequency. This data can be used to check if the resonance frequency has changed and drive parameters can be adapted accordingly. For the wind tunnel test, a common time synchronization signal will be provided by the wind tunnel system via the UDP protocol. Therefore the software monitors and logs also the UDP ports so that the acquired data of the measurement system can be easily linked to the specific experiments during the test campaign. Figure 7 shows the software user interface with the different sections:

(1) Enable/disable of amplifier boards with overload signal indicators;
(2) Setup of drive signal amplitude and frequency;

(3) Setup of measurement file path and sweep parameters;

(4) Setup of range for plots;

(5) Current and voltage plots for every amplifier with setup block for;

(6) (Drive signal and frequency/enable/overload indicator); (7) UDP monitoring.

\subsection{Laboratory testing of the system}

The drive electronics system was tested with the SJA insert box that is also used for the wind tunnel tests. Figure 8 shows the setup of the laboratory tests.

Due to manufacturing tolerances (e.g., dimensional and material composition tolerances) as well as assembly tolerances (e.g., tolerances in clamping of the transducer), the performance of the actuators is not the same. The panel was characterized by means of a hot-wire anemometer. The results are shown in Fig. 9 including the scattering of the performance. The drive electronics system was capable of driving all actuators without going into overload state. The actual capacitance of a typical actuator is approximately $85 \mathrm{nF}$, which was measured using an LCR meter. Up to four actuators are connected to one amplifier in parallel, which corresponds to a capacitive load of about $340 \mathrm{nF}$.

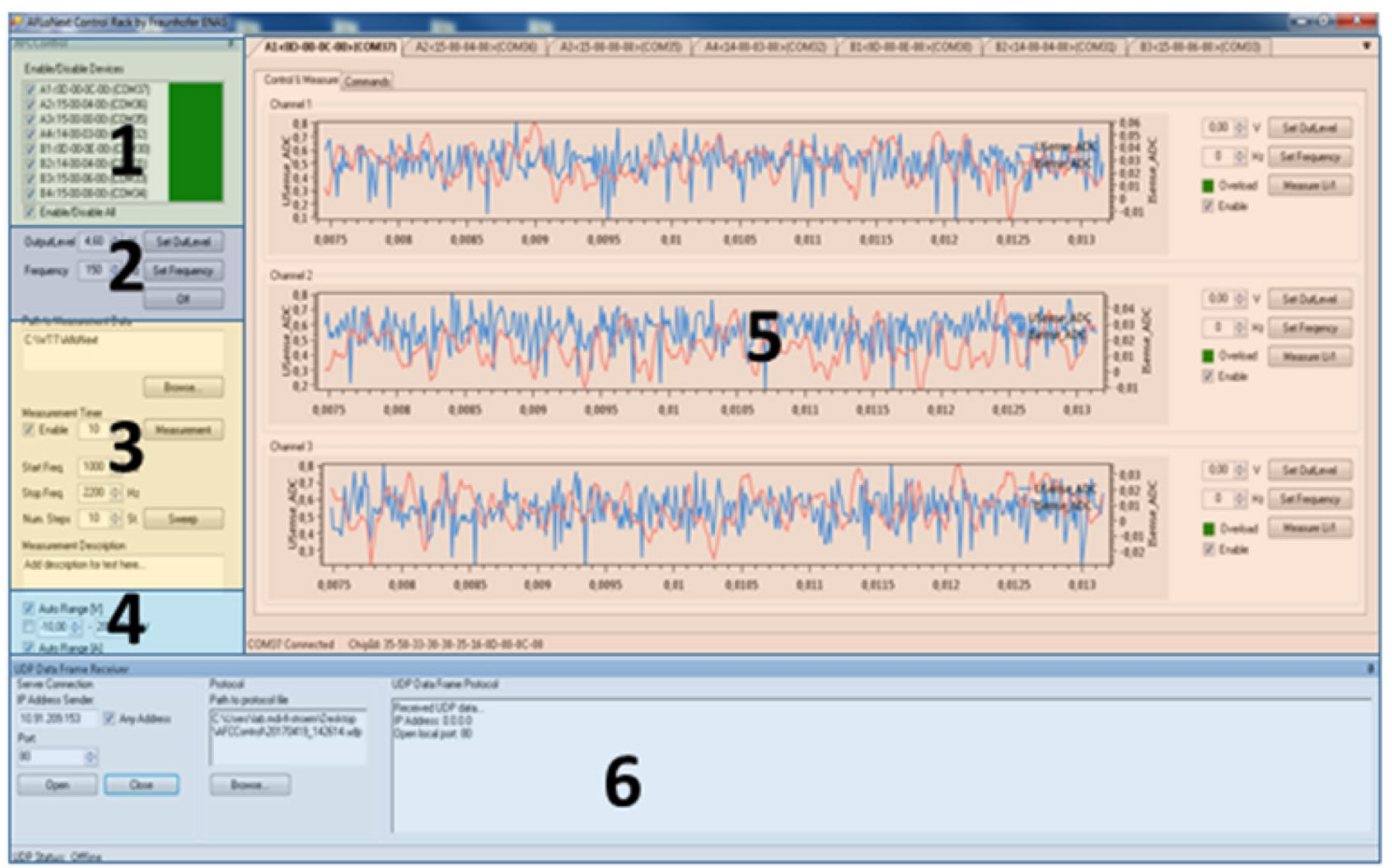

Fig. 7 Software interface 


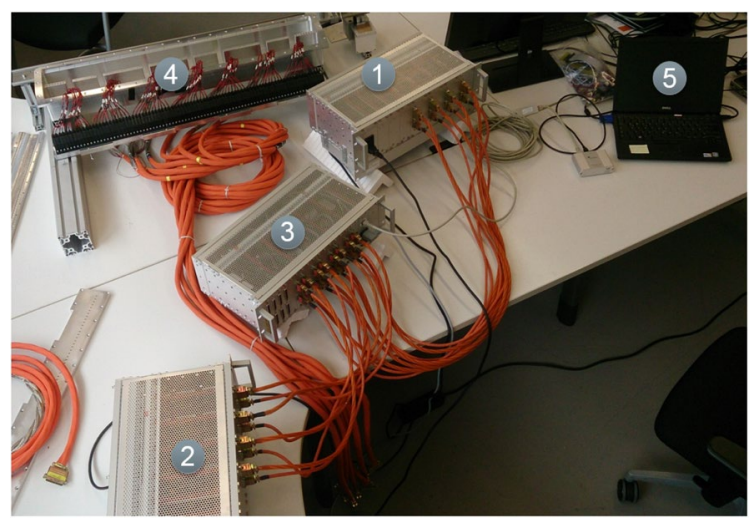

Fig. 8 Setup for ground test (1 and 2-amplifier subracks, 3-M\&C subrack, 4-SJA insert box with 84 actuators, 5-remote control computer)

\section{Active flow control on the outer wing}

\subsection{Concept for robustness test campaign}

For the second application scenario considered in AFLoNext, a panel with ten actuators in two rows of each five actuators was designed and manufactured (Fig. 10). This panel was designed for a harsh environmental test campaign conducted by INCAS in Bucharest. The panel integrates two different nozzle geometries, to analyze the influence of the nozzle geometry on the robustness. The first row has slots of $0.5 \mathrm{~mm}$ width and $10 \mathrm{~mm}$ length with $30^{\circ}$ nozzle inclination with respect to the surface. The second row basically has the same geometry, but with a $45^{\circ}$ inclination with respect to the surface. All actuators within the panel are connected to one common 25-pin D-Sub connector. Twenty pins are used for connecting every single actuator with a two-pin electrical interface. The remaining five pins are used for grounding the panel to protective earth, when the drive electronics system is connected. The system is driven by an amplifier system with attached measurement circuit for current and voltage monitoring. The drive system is an in-house development by Fraunhofer ENAS and has two integrated HV amplifiers with maximum peak output voltage of $150 \mathrm{~V}$. Ten measurement channels-five per amplifier output—for voltage and current monitoring are available. The system is connected via USB interface to a control computer and LabVIEW software is used to set up the drive signal and monitor the actuator signals and their current consumption (Fig. 10).

\subsection{Design of robust actuator}

The actuators are designed to be manufactured as an aluminum housing. The same transducers are used as for the actuators designed for integration in the wing-pylon configuration, i.e., transducers with a bimorph using a soft PZT with high $\mathrm{d} 31$ and a spring steel as substrate. The interface to the top cover is a channel of circular cross section with $4 \mathrm{~mm}$-diameter. The nozzle element adapts the geometry from this $4 \mathrm{~mm}$ hole to inclined slots of $0.5 \mathrm{~mm}$ width and $10 \mathrm{~mm}$ length with $30^{\circ}$ or $45^{\circ}$ inclination. The choice to use aluminum as the housing material was based on the extreme environmental conditions the actuators had to withstand during environmental DO1060 tests (Fig. 11).

\subsection{Results of test campaign}

Before starting the test campaign the actual performance of all ten actuators in the panel was characterized using a hot-wire anemometer. The distance between nozzle exit and
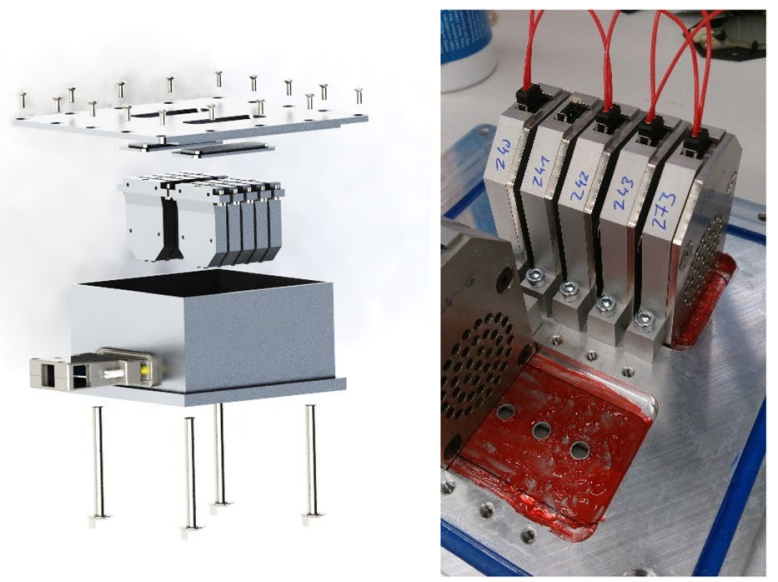

Fig. 10 Exploded view of actuator panel for a harsh environmental test campaign (left) and actuators mounted in top cover plate (right)
Fig. 9 Statistical test results of all 84 actuators of wing pylonjunction without cross flow (left)/hot-wire velocity measurement setup (right)
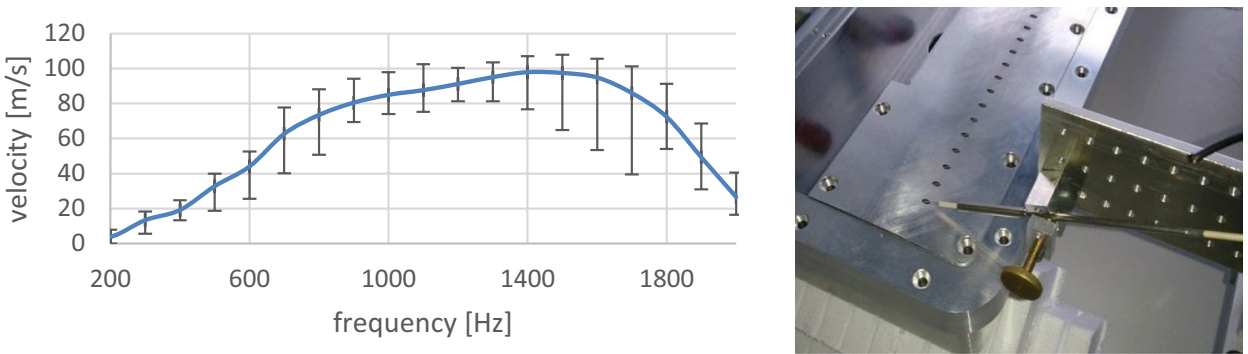
Fig. 11 SJA front view (left), side view (middle), prototype actuator (right)

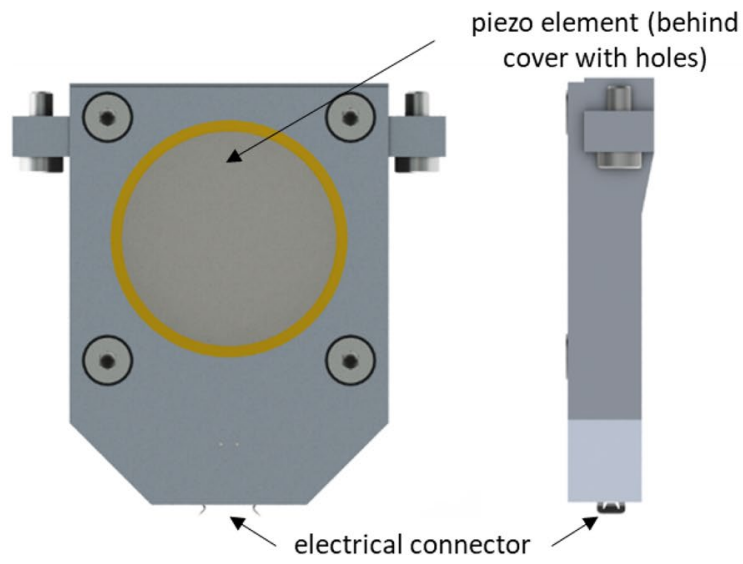

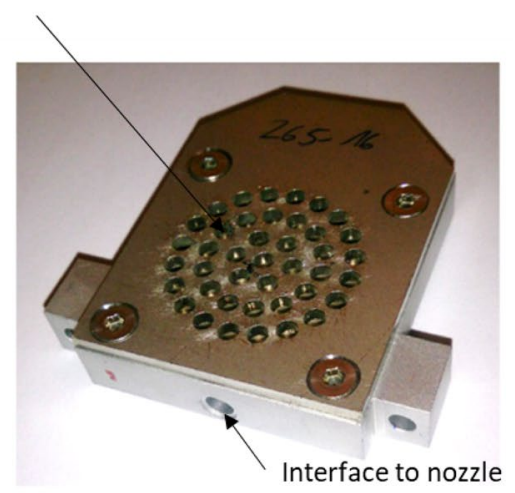

hot wire is approx. $1 \mathrm{~mm}$. To determine the influence of the harsh environment on the actuator panel, the characterization of the actuators was repeated after every test. The results showed whether the actuators still worked properly or whether the performance has changed. The results of these tests will reveal any critical points of the current design. They will be detailed to exactly identify the individual failure mechanisms and derive adaptions of the design.

The initial performance of the panel is shown in the graphs below. Due to the different nozzle geometries the resonance frequency is different for the actuators in the two rows. Also the performance is not the same. The detailed cause-effect relationships have to be examined more deeply in further research on this topic. The variability in the velocity-frequency response is quite large and the largest for the $30^{\circ}$ inclined nozzles. The main cause for this can be manufacturing tolerances of piezo elements and nozzles elements. The two resonance frequencies show some scatter, but are not very much different from the ones in Figs. 4 and 9. The actuator with the more tangentially directed nozzle appears to perform somewhat better than the actuator with the $45^{\circ}$-inclined nozzle (Fig. 12).

$45^{\circ}$ nozzle inclination

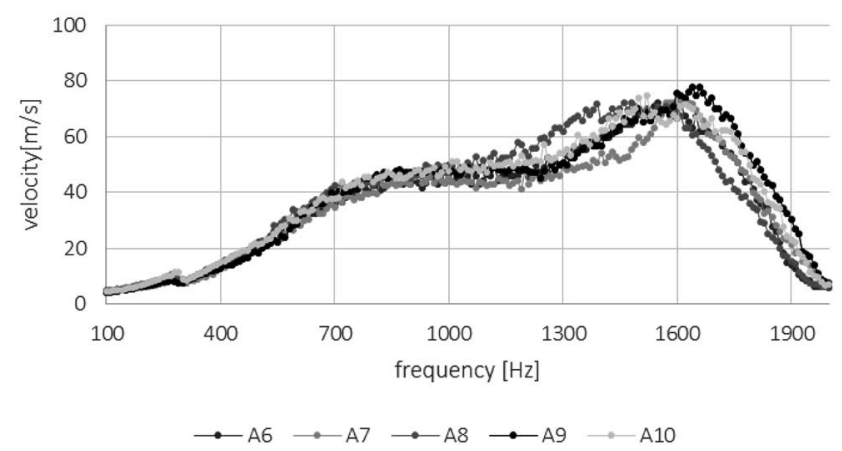

Most of the tests are performed using the EUROCAE ED-14G (RTCA DO-160G) environmental test standard for airborne equipment. More detailed information can be found in [22] in which the test campaign is described and some of the results are shown.

\section{Outlook}

The goal of the test campaign has been the evaluation of the technology and assessment of the technology readiness level (TRL). With the current results of the environmental test campaign, the technology readiness level of the actuator system is classified as TRL 3 . With positive results from the wind tunnel test, TRL 4 may be achieved. The further development of the actuators will focus on aircraft integration and on the identified drawbacks of the current design to find more robust solutions. The results of the project AFLoNext will be transferred to future projects to mature the technology towards higher technology readiness levels. This will include a miniaturization of peripheral electronic systems and a further optimization of the actuator performance with

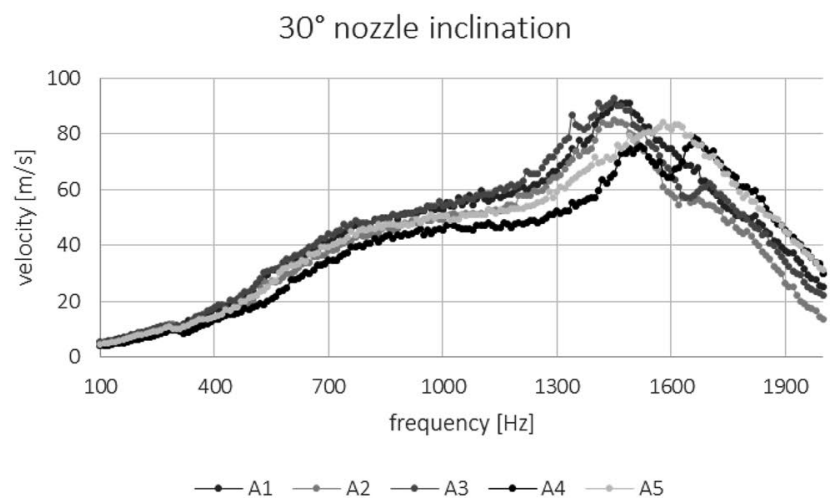

Fig. 12 Results characterization of the actuator panel before the harsh environmental test campaign. Driving voltage: $150 \mathrm{~V}_{\mathrm{pp}}$. Left: $45^{\circ}$ inclined nozzle. Right: $30^{\circ}$ inclined nozzle 
integration of additional internal sensors for enhanced monitoring and control.

Funding Open Access funding enabled and organized by Projekt DEAL.

Open Access This article is licensed under a Creative Commons Attribution 4.0 International License, which permits use, sharing, adaptation, distribution and reproduction in any medium or format, as long as you give appropriate credit to the original author(s) and the source, provide a link to the Creative Commons licence, and indicate if changes were made. The images or other third party material in this article are included in the article's Creative Commons licence, unless indicated otherwise in a credit line to the material. If material is not included in the article's Creative Commons licence and your intended use is not permitted by statutory regulation or exceeds the permitted use, you will need to obtain permission directly from the copyright holder. To view a copy of this licence, visit http://creativecommons.org/licenses/by/4.0/.

\section{References}

1. Smith, B.L., Glezer, A.: The formation and evolution of synthetic jets. Phys. Fluids 10(9), 2281-2297 (1998)

2. Glezer, A., Amitay, M.: Synthetic jets. Ann. Rev. Fluid Mech. 34, 503-529 (2002)

3. Amitay, M., Smith, D.R., Kibens, V., Parekh, D.E., Glezer, A.: Aerodynamic flow control over an unconventional airfoil using synthetic jet actuators. AIAA J. 39(3), 361-370 (2001)

4. Seifert, A., Pack, L.G.: Oscillatory control of separation at high Reynolds numbers. AIAA J. 37(9), 1062-1071 (1999)

5. Mahalingam, R., Rumigny, N., Glezer, A.: Thermal management using synthetic jet ejectors. IEEE Trans. Compon. Packag. Technol. 27(3), 439-444 (2004)

6. Smith, B.L., Glezer, A.: Jet vectoring using synthetic jets. J. Fluid Mech. 458, 1-34 (2002)

7. Travnicek, Z., Tesar, V.: Annular synthetic jet used for impinging flow mass-transfer. Int. J. Heat Mass Transf. 46(17), 3291-3297 (2003)

8. Fang, R., Khan, J.A.: Suppression of two-phase flow instabilities in parallel microchannels by using synthetic jets. J. Heat Transf. 135(11), 111016 (2013). https://doi.org/10.1115/1.4024624 (Paper No: HT-12-1338 (Sep 23, 2013) (13 pages))

9. van Buren, T., Whalen, W., Amitay, M.: Achieving a high-speed and momentum synthetic jet actuator. J. Aerosp. Eng. (2016). https://doi.org/10.1061/(ASCE)AS.1943-5525.0000530

10. Oyarzum, M.A., Cattafesta, L.: Design and optimization of piezoelectric zero-net mass-flux actuators. AIAA J. (2010). https://doi. org/10.2514/6.2010-4414
11. Deng, J., Yuan, W., Luo, J., Shen, D., Ma, B.: Design and fabrication of a Piezoelectric Micro Synthetic Jet Actuator. In: 2011 6th IEEE International Conference on Nano/Micro Engineered and Molecular Systems. IEEE, Kaohsiung (2011). https://doi. org/10.1109/NEMS.2011.6017353

12. Girfoglio, M.: On the characterization of a synthetic jet actuator driven by a piezoelectric disk (2015). https://doi.org/10.6092/ UNINA/FEDOA/10228

13. Bhatt, S., Golubev, V.V., Tang, Y.: Design, modeling and testing of synthetic jet actuators for MAV flight control. In: 52nd Aerospace Sciences Meeting, 13-17 Jan 2014, National Harbor, Maryland. American Institute of Aeronautics and Astronautics AIAA, Reston (2014). https://doi.org/10.2514/6.2014-1144

14. Gallas, Q., Holman, R., Nishida, T., Carroll, B., Sheplak, M., Cattafesta, L.: Lumped element modeling of piezoelectric-driven synthetic jet actuators. AIAA J. 41(2), 240-247 (2003). https:// doi.org/10.2514/2.1936

15. de Luca, L., Girfoglio, M., Coppola, G.: Modeling and experimental validation of the frequency response of synthetic jet actuators. AIAA J. 10(2514/1), J052674 (2014)

16. Liang, Y., Taya, M., Kuga, Y.: Design of diaphragm actuator based on ferromagnetic shape memory alloy composite. In: Anderson, E.H. (ed.) Smart structures and materials, p. 45. SPIE (2003)

17. Ashraf, H.M., Illikkal, K.M., D'souza, F., Mahmood, M.A., Mostafa, S.M., Kim, Y.H., Petra, D., Tomáš, V.: Design \& development of a high mass flow piston synthetic jet actuator. EPJ Web Conf. (2015). https://doi.org/10.1051/epjconf/20159202002

18. Gilarranz, J., Rediniotis, O.: Compact, high-power synthetic jet actuators for flow separation control. In: 39th Aerospace sciences meeting and exhibit (2001)

19. Agashe, J.S.: Modeling, design and optimization of electrodynamic zero-net mass-flux (ZNMF) actuators. (2009)

20. PIEZODRIVE. PiezoDrive MX200 [online]. 200V 1A piezo driver. https://www.piezodrive.com/wp-content/uploads/2016/01/ MX200.pdf. Accessed 17 July 2017

21. SCHROFF. Maxpower MAX180 datasheet [online]. Document 63972-225_R1.2 https://schroff.pentair.com. Accessed 20 Sept 2011

22. Brinza, I., Schloesser, P., Weigel, P.: Testing of active flow control actuators at harsh environments. In: Proceedings of CEAS2017 conference

Publisher's Note Springer Nature remains neutral with regard to jurisdictional claims in published maps and institutional affiliations. 